Published in final edited form as:

Curr Opin Organ Transplant. 2017 December ; 22(6): 513-521. doi:10.1097/MOT.0000000000000463.

\title{
XENOTRANSPLANTATION: PAST, PRESENT, AND FUTURE
}

\author{
Burcin Ekser, MD, PhD ${ }^{1}$, Ping Li, PhD ${ }^{1}$, and David K.C. Cooper, MD, PhD ${ }^{2}$ \\ ${ }^{1}$ Division of Transplant Surgery, Department of Surgery, Indiana University School of Medicine, \\ Indianapolis, IN, USA \\ ${ }^{2}$ Xenotransplantation Program, Department of Surgery, The University of Alabama at \\ Birmingham, Birmingham, AL, USA
}

\begin{abstract}
Purpose of review-To review the progress in the field of xenotransplantation with special attention to most recent encouraging findings which will eventually bring xenotransplantation to the clinic in the near future.
\end{abstract}

Recent findings-Starting from early 2000, with the introduction of Gal-knockout pigs, prolonged survival especially in heart and kidney xenotransplantation was recorded. However, remaining antibody barriers to nonGal antigens continue to be the hurdle to overcome. The production of genetically-engineered pigs was difficult requiring prolonged time. However, advances in gene editing, such as zinc finger nucleases, transcription activator-like effector nucleases, and most recently CRISPR technology made the production of genetically-engineered pigs easier and available to more researchers. Today, the survival of pig-to-nonhuman primate heterotopic heart, kidney, and islet xenotransplantation reached $>900$ days, $>400$ days, and $>600$ day, respectively. The availability of multiple-gene pigs ( 5 or 6 genetic modifications) and/or newer costimulation blockade agents significantly contributed to this success. Now, the field is getting ready for clinical trials with an international consensus.

Summary-Clinical trials in cellular or solid organ xenotransplantation are getting closer with convincing preclinical data from many centers. The next decade will show us new achievements and additional barriers in clinical xenotransplantation.

\section{Keywords}

clinical; CRISPR; experimental; genetic engineering; xenotransplantation

\section{Introduction}

Outcomes of organ and cell allotransplantation continue to improve. However, the shortage of transplantable organs remains as the major hurdle in the field of transplantation despite the use of marginal deceased donors and living donors [1]. Xenotransplantation (i.e., cross-

Address for correspondence: Burcin Ekser MD PhD, Division of Transplant Surgery, Department of Surgery, Indiana University School of Medicine, 550 N. University Blvd, UH 4601, Indianapolis, IN 46202, USA, bekser@iupui.edu, Tel: +1-317-948-3835, Fax: $+1-317-968-1254$.

Conflict of interest

The authors declare no conflict of interest. 
species transplantation between pig and humans) could offer an unlimited and prompt supply of transplantable organs, when needed [2]. In addition to organ transplantation, many disorders could be treated by xenotransplantation (Figure 1).

In this review, we (i) briefly mention the past experience with xenotransplantation (mainly by referring to seminal review articles), (ii) provide a review of the most recent (within the last 24 months) advances in the field (present), and suggest future applications in the clinic (future).

Past

The concept of xenotransplantation is not new, and there have been numerous clinical attempts during the past 300 years or more [3]. Clinical blood xenotransfusion was attempted in the $17^{\text {th }}$ century by Jean Baptiste Denis, corneal xenotransplantation from pigto-human followed in the early $19^{\text {th }}$ century, and attempts were made at nonhuman primate (NHP) kidney xenotransplantation in the 1960s by Reemtsma [3,4] and others [5]. The world experience in pig-to-NHP models of xenotransplantation (until 1997) was reviewed by Lambrigts et al. [6], and a comprehensive review regarding progress in pig-to-NHP since then (1998-2013) was published in 2014 [7].

\section{Present}

Xenotransplantation research was stimulated by the production of pigs in which the important antigen, galactose-a 1,3-galactose (Gal), had been deleted by gene-knockout (GTKO pigs) in 2003 [8]. More recently, the identification of other xenoantigens has also been important.

Techniques for making genetically-engineered pigs have become easier and faster. Rapid improvement in the results of preclinical studies has made the field more hopeful of the initiation of clinical trials [8-11]. Recent papers have discussed the selection of patients for initial clinical trials for solid organ xenotransplantation [12] and islet xenotransplantation. We here briefly review progress in pig-to-NHP models.

Heart xenotransplantation-Mohiuddin et al [13] demonstrated that long-term survival of genetically-engineered pig heterotopic heart grafts could be achieved in NHPs. Genetic modifications in the pig (GTKO.hCD46.hThrombomodulin) combined with a successful treatment regimen based on a chimeric anti-CD40 monoclonal antibody (mAb), consistently prevented humoral rejection and systemic coagulation pathway dysregulation, sustaining cardiac xenograft survival in one case beyond 900 days (Figure 2) [13].

Iwase et al. tested three different costimulation blockade-based immunosuppressive regimens in the pig-to-baboon heterotopic heart xenotransplantation model, and demonstrated that the combination of anti-CD40mAb+belatacept proved effective in preventing a T cell response [14]. Despite significant progress on the survival of heterotopic pig heart xenotransplantation, orthotopic heart xenotransplantation experiments were limited and the longest survival recorded to date was $<60$ days. Murthy et al recently reviewed the historical background, experimental progress, and clinical prospects in heart xenotransplantation [15]. 
Kidney xenotransplantation-The last 2 years have shown us that we are close to clinical trials of genetically-engineered pig kidney xenotransplantation. Two groups separately showed prolonged survival of life-supporting renal xenografts compared with historical 90-day survival [2,6] in different pig-to-NHP models [16,17]. The Emory group performed pre-transplant antibody screening in recipient monkeys and showed that the combination of low titer antibody and anti-CD154mAb costimulation blockade promoted long-term renal xenograft survival [16]. The Pittsburgh group showed that specific genetic modifications of the pig are important in achieving prolonged survival [17]. Most recently, Kim et al reported the longest survival (405 days) of a life-supporting pig kidney xenograft in a preclinical model, emphasizing the importance of $\mathrm{CD}^{+} \mathrm{T}$ cell depletion (Figure 2) [18].

Tanabe et al. studied the role of intrinsic (graft) versus extrinsic (host) factors in the growth of renal xenografts in GTKO pig-to-baboon model and identified that not only the sizemismatch (extrinsic - host factors), but also the intrinsic (graft) factors are responsible for growth of donor organs with a threshold for renal xenograft volume of $25 \mathrm{~cm}^{3} / \mathrm{kg}$ of recipient body weight at which cortical ischemia was induced [19]. Iwase et al reported the immunological and physiological observations in baboons with life-supporting geneticallyengineered pig kidney grafts with particular attention to the use of multiple-gene pigs, an effective costimulation blockade-based immunosuppressive regimen, and anti-inflammatory therapy in preventing immune injury [20]. In a recent review, Wijkstrom et al discussed the experimental progress and clinical prospects in renal xenotransplantation [21].

Lung xenotransplantation-Most recently, only the Maryland group has been active in exploring lung xenotransplantation. Burdorf et al. showed that platelet sequestration and activation during GTKO.hCD46 pig lung perfusion by human blood was primarily mediated by GPIb, GPIIb/IIIa, and von Willebrand Factor [22]. Laird et al showed that transgenic expression of human leukocyte antigen (HLA)-E attenuates GTKO.hCD46 pig lung xenograft injury [23]. A recent review from the same group concluded that genetic modification of pigs coupled with drugs targeting complement activation, coagulation, and inflammation have significantly increased duration of pig lung function in ex vivo human blood perfusion models, and life-supporting lung xenograft survival in vivo [24]. However, lung xenotransplantation is still measured in days rather than weeks or months.

Liver xenotransplantation-Although limited, fairly consistent 7-9 days' survival has been reported by different groups using GTKO and GTKO.hCD46 pig liver xenografts in NHPs after orthotopic pig liver xenotransplantation [25]. The Boston group increased survival to 29 days by the exogenous administration of human coagulation factors using the same model [26]. They reported two GTKO pig liver xenografts that survived $>25$ days (longest 29 days) (Figure 2), with immunosuppressive therapy consisting of anti-CD40mAb or belatacept [27]. Although there remain problems with this regimen, clinical trials of bridging to allotransplantation with a pig liver graft might become a possibility [28].

Islet xenotransplantation-In 2016, the International Xenotransplantation Association (IXA) published the first update on its consensus statement on conditions for undertaking clinical trials of porcine islet products in patients with type 1 diabetes [29-36]. This comprehensive report included (i) an update on national regulatory frameworks pertinent to 
clinical islet xenotransplantation [30], (ii) evaluation of the source of pigs in order to prevent xenozoonoses [31], (iii) genetically-modified pigs as the source of islets [32], (iv) production and manufacturing of porcine islets [33], (v) requirement and efficacy of the preclinical data to justify a clinical trial [34], (vi) recipient monitoring and response plan for preventing disease transmission [35], and, finally, (vii) patient selection for pilot clinical trials of pig islet xenotransplantation [36].

Matsumoto et al published a clinical trial using encapsulated neonatal wild-type pig islets in patients with type 1 diabetes [37]. Their study showed that there was a clinical benefit of islet xenotransplantation with improved HbA1c, especially when a greater number of islets was transplanted [37]. Although recipients did not become normoglycemic, the study provided some hope for future clinical trials [38].

While progress of encapsulation (micro or macro) is still under investigation [39], studies have recently been published on the use of different materials, such as agarose encapsulation, the microbiological safety of porcine islets [40], and the anti-fibrotic effect of rapamycin-containing polyethylene glycol-coated alginate microcapsules [41]. New drugs, such as cell-penetrating tat-metallothionein for immunomodulation have been studied, together with xeno-islet encapsulation $[42,43]$.

Although a recent pre-clinical study by Shin et al showed long-term control of diabetes in NHPs by the transplantation of wild-type adult porcine islets [44], a study by Kang et al showed that higher D-dimer levels negatively correlated with survival of porcine islet xenografts [45]. Despite more data becoming available on pig islet xenotransplantation in NHPs, the streptozotocin-induced diabetes model in NHP is still under debate [46].

The field is being advanced by the use of newly-available genetically-modified pigs and newer costimulation blockade agents. Lee et al used pig islets overexpressing human hemeoxygenase-1 and soluble tumor necrosis factor-alpha receptor type 1 with human IgG1 $\mathrm{Fc}$ in order to suppress early apoptosis during engraftment of xeno-islets [47]. Arefanian et al showed that porcine islet-specific tolerance induced by the combination of antilymphocyte function-associated antigen-1 and anti-CD154mAb is dependent on PD-1 (programmed cell death protein-1) [48]. Two recent reviews by Hawthorne et al [49] on genetic strategies to bring islet xenotransplantation to the clinic, and Bottino et al [50] on the safe use of anti-CD154mab underline the importance of genetic engineering and costimulation blockade in islet xenotransplantation. Recently, a seminal review was published by Liu et al on the past, present, and future of pig-to-primate islet xenotransplantation [51].

Tissue (cornea, heart valve, skin) xenotransplantation-Porcine corneal xenotransplantation shows promising application in the clinic. Lee et al studied the impact of the expression of $\mathrm{N}$-glycolylneuraminic acid on pig corneas, concluding that the absence of $\mathrm{N}$-glycolylneuraminic acid expression on GTKO pig corneas may not prove an advantage over GTKO pig corneas [52,53]. Dong et al recently published their initial results of GTKO.hCD46 pig full-thickness corneal xenografts in NHPs, which were comparable to the survival of wild-type pig corneas [54]. Lee et al provided evidence that the limiting factor of 
survival of pig corneas was the development of a retrocorneal membrane [55]. The Seoul group recently reported prolonged survival ( $>389$ days) of porcine deep-lamellar corneal xenografts in NHPs under immunosuppressive therapy with anti-CD40mAb (Figure 2) [56]. The same group also published the biophysico-functional compatibility of their miniature pig corneas as grafts in clinical trials [57].

Reuven et al [58] and Lee et al [59] studied the impact of N-glycolylneuraminic acid expression in bioprosthetic pig heart valves on human antibody recognition and structural deterioration.

Tena et al demonstrated that pig cells expressing human CD47 are associated with an immune-modulating effect, which leads to markedly-prolonged survival of pig skin grafts in NHPs [60].

Cellular (hepatocyte, neuronal cell) xenotransplantation-Machaidze et al tested porcine hepatocytes in alginate-poly-1-lysine microspheres transplanted intraperitoneally immediately after hepatectomy in a model of fulminant liver failure in baboons [61]. The microencapsulated porcine hepatocytes provided temporary functional support [61]. Mahou et al. reviewed the contribution of polymeric materials in the xenotransplantation of microencapsulated cells (mainly hepatocytes and islets), and addressed the state-of-the-art in cell microencapsulation with special focus on the choice of materials, and the design and fabrication of the microspheres [62]. Iwase et al. transplanted genetically-engineered pig hepatocytes directly into the spleen and other sites in immunosuppressed baboons, and reported very early graft failure [63].

The European Consortium (Xenome Project) studied the feasibility of pig neuronal cell xenotransplantation in NHPs to cure Parkinson's disease [64]. Parkinsonian NHPs received wild-type or CTLA4-Ig-transgenic porcine xenografts and different durations of exogenous immunosuppressive therapy to test whether systemic plus graft-mediated local immunosuppression might avoid rejection. A striking recovery of spontaneous locomotion was observed in the NHPs that received systemic plus local immunosuppression for 6 months, which was also associated with restoration of dopaminergic activity [64]. However, some recipients developed post-transplant lymphoproliferative disease, probably due to overimmunosuppression [65].

Inflammation and coagulation-Further attention was directed to inflammation in xenotransplantation. Ezzelarab et al. showed that systemic inflammation in xenograft recipients precedes activation of coagulation [66]. Iwase et al. measured serum free triiodothyronine (thyroid hormone) as a marker of inflammation in healthy naïve baboons, healthy naïve monkeys, and after pig-to-baboon heterotopic heart xenotransplantation, orthotopic liver xenotransplantation, artery patch xenotransplantation, and in monkey heterotopic heart allotransplantation [67]. They showed that there is a dramatic fall in serum thyroid hormone levels following operative procedures. A persistent low level of thyroid hormone after pig heart and liver xenotransplantation may be associated with a continuing inflammatory state, which might be corrected with extraneous replacement of thyroid hormone [67]. Other inflammatory states and markers, particularly of extracellular histones, 
have been discussed with their potential therapeutic regulation in xenotransplantation $[68,69]$.

Zoonosis-The potential for the transmission of infection from animal-to-human has always been of concern. Therefore, several porcine viruses have been studied in regard to xenotransplantation. Denner et al. published seminal reviews on virological safety in xenotransplantation [70,71]. Particular attention has been directed to porcine endogenous retroviruses (PERV) [72], their susceptibility to retroviral inhibitors [73], and their genomewide inactivation by genetic technology [74]. Morozov et al. showed that there was no PERV transmission during a clinical trial of pig islet xenotransplantation [75]. Similarly, no PERV transmission was shown by Choi et al. in pig-to-NHP corneal xenotransplantation [76]. Morozov et al. also published an extended characterization of porcine cytomegalovirus and other viruses in specially-bred pigs [77].

Porcine circoviruses (both type 1 and 2) were recently studied [78]. Whereas type 1 is not pathogenic in pigs, type 2 may induce severe disease. Although there is evidence that type 2 porcine circovirus does not infect (at least immunocompetent) humans, the recommendation is that pigs that will be sources of xenografts should be screened using sensitive methods to ensure virus elimination [78].

Ethics and regulatory aspects-As initial clinical trials draw closer, ethics [79], acceptance of xenotransplantation by hospital personnel [80], and by the general population with different cultural and religious backgrounds [81-83], are topics of importance.

Schuurman has recently comprehensively reviewed regulatory aspects of xenotransplantation in Europe and in the United States in his seminal papers [84-85].

Genetic engineering-The introduction of CRISPR (clustered regularly interspaced short palindromic repeats) technology in xenotransplantation has increased the speed in which genetic manipulations can be achieved in pigs. In the early years, genetic engineering of pigs was performed by homologous recombination, which might take longer than 2 years from cell work to pregnancy [86]. Table 1 summarizes the timeline of the evolving genetic engineering techniques in xenotransplantation. Today, research groups can produce multiple gene knock-out or knock-in pigs using CRISPR technology [87-94], which can also be used to delete PERV expression [74,95]. Genetically-modified pigs using CRIPSR technology have been used in several important studies relating to antibody binding [96-98] and coagulation dysfunction $[99,100]$. There are now more than 26 genetically-engineered pigs for xenotransplantation research (Table 2). Cooper recently published a review on carbohydrate antigen targets on pig cells [101]. Cowan et al also published a commentary on the importance of modifying the glycome in pigs for xenotransplantation [102].

\section{Conclusion}

\section{Future of xenotransplantation}

With our accumulated experience $[2,103]$ and recent achievements $[13,18,86]$ in xenotransplantation, the stage may now be set for the first-in-human exploration [11]. Although a small clinical trial of microencapsulated wild-type pig islet xenotransplantation 
is currently underway [37,38], the future is set for well-controlled trials of geneticallyengineered pig islet xenotransplantation. The xenotransplantation research community needs to decide (i) whether successful orthotopic heart transplantation in the pig-to-NHP model is required before proceeding to a clinical trial [104], and (ii) whether the preclinical threshold for a clinical renal xenotransplantation trial can be reduced [105].

The resurgence of xenotransplantation is now obvious [9,10,106], with prolonged survival of cellular and solid organ xenografts (Figure 2) associated with the administration of newer costimulation blockade agents $[107,108]$ and access to genetically-engineered pigs. Our increasing knowledge of the pig genome [109] will almost certainly lead to further genetic manipulations. The future of xenotransplantation is vibrant.

\title{
Acknowledgments
}

Work on xenotransplantation in the Xenotransplantation Research Laboratory at Indiana University has been supported by internal funds of the Department of Surgery. Work on xenotransplantation at the University of Alabama at Birmingham is supported in part by NIH NIAID U19 grant AI090959.

\author{
Abbreviations \\ GTKO a1,3-galactosyltransferase gene-knockout \\ mAb monoclonal antibody \\ NHP nonhuman primate \\ PERV porcine endogenous retrovirus
}

\section{References and Recommended Reading}

Papers of particular interest, published within the annual period of review, have been highlighted as:

* of special interest

** of outstanding interest

1. Ekser B, Cooper DK, Tector AJ. The need for xenotransplantation as a source of organs and cells for clinical transplantation. Int J Surg. 2015 Nov; 23(Pt B):199-204. [PubMed: 26188183]

2. Ekser B, Ezzelarab M, Hara H, et al. Clinical xenotransplantation: the next medical revolution? Lancet. 2012; 379:672-683. [PubMed: 22019026]

3. Cooper DKC, Ekser B, Tector AJ. A brief history of clinical xenotransplantation. Int J Surg. 2015 Nov; 23(Pt B):205-210. [PubMed: 26118617]

4. Hara H, Cooper DK. The immunology of corneal xenotransplantation: a review of the literature. Xenotransplantation. 2010; 17:338-349. [PubMed: 20955291]

5. Cooper DKC. Early clinical xenotransplantation experiences-An interview with Thomas E. Starzl, MD, PhD. Xenotransplantation. 2017; 24doi: 10.1111/xen.12306

6. Lambrigts D, Sachs DH, Cooper DK. Discordant organ xenotransplantation in primates: world experience and current status. Transplantation. 1998; 66:547-561. [PubMed: 9753331]

7. Cooper DKC, Satyananda V, Ekser B, et al. Progress in pig-to-non-human primate transplantation models (1998-2013): a comprehensive review of the literature. Xenotransplantation. 2014; 21:397419. [PubMed: 25176336] 
8. Cooper DK, Ekser B, Ramsoondar J, Phelps C, Ayares D. The role of genetically engineered pigs in xenotransplantation research. J Pathol. 2016; 238:288-299. * Important review on the impact of the role of genetically-engineered pigs in xenotransplantation and their development. [PubMed: 26365762]

9. Perkel JM. Xenotransplantation makes a comeback. Nat Biotechnol. 2016; 34:3-4. * An editorial which underlines the importance of xenotransplantation. [PubMed: 26744956]

10. Xenotransplantation 2.0. Nat Biotechnol. 2016; 34:1. [No authors listed]. doi: 10.1038/nbt.3466

11. Schuurman HJ. Pig-to-nonhuman primate solid organ xenografting: recent achievements on the road to first-in-man explorations. Xenotransplantation. 2016; 23:175-178. [PubMed: 27273650]

12. Cooper DKC, Wijkstrom M, Hariharan S, et al. Selection of Patients for Initial Clinical Trials of Solid Organ Xenotransplantation. Transplantation. 2017; 101:1551-1558. * Brings attention to the selection of recipients for initial clinical trials in solid organ xenotransplantation. [PubMed: 27906824]

13. Mohiuddin MM, Singh AK, Corcoran PC, et al. Chimeric 2C10R4 anti-CD40 antibody therapy is critical for long-term survival of GTKO.hCD46.hTBM pig-to-primate cardiac xenograft. Nat Commun. 2016; 7:11138. ** Reports an extensive experience and the longest survival in heterotopic heart xenografts in a preclinical study with the use of a newer costimulation blockade agent. [PubMed: 27045379]

14. Iwase H, Ekser B, Satyananda V, et al. Pig-to-baboon heterotopic heart transplantation--exploratory preliminary experience with pigs transgenic for human thrombomodulin and comparison of three costimulation blockade-based regimens. Xenotransplantation. 2015; 22:211-220. [PubMed: 25847282]

15. Murthy R, Bajona P, Bhama JK, Cooper DK. Heart Xenotransplantation: Historical Background, Experimental Progress, and Clinical Prospects. Ann Thorac Surg. 2016; 101:1605-1613. [PubMed: 26785937]

16. Higginbotham L, Mathews D, Breeden CA, et al. Pre-transplant antibody screening and antiCD154 costimulation blockade promote long-term xenograft survival in a pig-to-primate kidney transplant model. Xenotransplantation. 2015; 22:221-230. [PubMed: 25847130]

17. Iwase H, Liu H, Wijkstrom M, et al. Pig kidney graft survival in a baboon for 136 days: longest life-supporting organ graft survival to date. Xenotransplantation. 2015; 22:302-309. [PubMed: 26130164]

18. Kim S, Higginbotham L, Mathews D, et al. CD4 Depletion Is Necessary and Sufficient for LongTerm Nonhuman Primate Xenotransplant Survival. [abstract]. Am J Transplant. 2017; 17(suppl 3) [Accessed June 1, 2017] http://atcmeetingabstracts.com/abstract/cd4-depletion-is-necessary-andsufficient-for-long-term-nonhuman-primate-xenotransplant-survival/ ** Reports the longest survival in life-supporting kidney xenotransplantation.

19. Tanabe T, Watanabe H, Shah JA, et al. Role of Intrinsic (Graft) Versus Extrinsic (Host) Factors in the Growth of Transplanted Organs Following Allogeneic and Xenogeneic Transplantation. Am J Transplant. 2017; 17:1778-1790. [PubMed: 28117931]

20. Iwase H, Hara H, Ezzelarab M, et al. Immunological and physiological observations in baboons with life-supporting genetically engineered pig kidney grafts. Xenotransplantation. 2017; 24doi: 10.1111/xen.12293

21. Wijkstrom M, Iwase H, Paris W, Hara H, Ezzelarab M, Cooper DK. Renal xenotransplantation: experimental progress and clinical prospects. Kidney Int. 2017; 91:790-796. [PubMed: 27914702]

22. Burdorf L, Riner A, Rybak E, et al. Platelet sequestration and activation during GalTKO.hCD46 pig lung perfusion by human blood is primarily mediated by GPIb, GPIIb/IIIa, and von Willebrand Factor. Xenotransplantation. 2016; 23:222-236. [PubMed: 27188532]

23. Laird CT, Burdorf L, French BM, et al. Transgenic expression of human leukocyte antigen-E attenuates GalKO.hCD46 porcine lung xenograft injury. Xenotransplantation. 2017; 24doi: 10.1111/xen.12294

24. Laird C, Burdorf L, Pierson RN 3rd. Lung xenotransplantation: a review. Curr Opin Organ Transplant. 2016; 21:272-278. [PubMed: 26967998] 
25. Cooper DK, Dou KF, Tao KS, Yang ZX, Tector AJ, Ekser B. Pig Liver Xenotransplantation: A Review of Progress Toward the Clinic. Transplantation. 2016; 100:2039-2047. [PubMed: 27428714]

26. Navarro-Alvarez N, Shah JA, Zhu A, et al. The Effects of Exogenous Administration of Human Coagulation Factors Following Pig-to-Baboon Liver Xenotransplantation. Am J Transplant. 2016; 16:1715-1725. [PubMed: 26613235]

27. Shah JA, Patel MS, Elias N, et al. Prolonged Survival Following Pig-to-Primate Liver Xenotransplantation Utilizing Exogenous Coagulation Factors and Costimulation Blockade. Am J Transplant. 2017 May 10. ** Reports the longest survival in liver xenotransplantation in a preclinical study with the use of human coagulation factor infusion and a newer costimulation blockade agent. doi: 10.1111/ajt.14341

28. Ekser B, Gridelli B, Tector AJ, Cooper DK. Pig liver xenotransplantation as a bridge to allotransplantation: which patients might benefit? Transplantation. 2009; 88:1041-1049. [PubMed: 19898198]

29. Hering BJ, Cozzi E, Spizzo T, et al. First update of the International Xenotransplantation Association consensus statement on conditions for undertaking clinical trials of porcine islet products in type 1 diabetes-Executive summary. Xenotransplantation. 2016; 23:3-13. ** Executive summary of several seminal articles (references 30-36) of the first update of the IXA international consensus. [PubMed: 26940725]

30. Cozzi E, Tönjes RR, Gianello P, et al. First update of the International Xenotransplantation Association consensus statement on conditions for undertaking clinical trials of porcine islet products in type 1 diabetes--Chapter 1: update on national regulatory frameworks pertinent to clinical islet xenotransplantation. Xenotransplantation. 2016; 23:14-24. [PubMed: 26940509]

31. Spizzo T, Denner J, Gazda L, et al. First update of the International Xenotransplantation Association consensus statement on conditions for undertaking clinical trials of porcine islet products in type 1 diabetes--Chapter 2a: source pigs--preventing xenozoonoses. Xenotransplantation. 2016; 23:25-31. [PubMed: 26940608]

32. Cowan PJ, Ayares D, Wolf E, Cooper DK. First update of the International Xenotransplantation Association consensus statement on conditions for undertaking clinical trials of porcine islet products in type 1 diabetes--Chapter $2 \mathrm{~b}$ : genetically modified source pigs. Xenotransplantation. 2016; 23:32-37. [PubMed: 26926888]

33. Rayat GR, Gazda LS, Hawthorne WJ, et al. First update of the International Xenotransplantation Association consensus statement on conditions for undertaking clinical trials of porcine islet products in type 1 diabetes--Chapter 3: Porcine islet product manufacturing and release testing criteria. Xenotransplantation. 2016; 23:38-45. [PubMed: 26923763]

34. Cooper DK, Bottino R, Gianello P, et al. First update of the International Xenotransplantation Association consensus statement on conditions for undertaking clinical trials of porcine islet products in type 1 diabetes--Chapter 4: pre-clinical efficacy and complication data required to justify a clinical trial. Xenotransplantation. 2016; 23:46-52. [PubMed: 26916706]

35. Denner J, Tönjes RR, Takeuchi Y, Fishman J, Scobie L. First update of the International Xenotransplantation Association consensus statement on conditions for undertaking clinical trials of porcine islet products in type 1 diabetes--Chapter 5: recipient monitoring and response plan for preventing disease transmission. Xenotransplantation. 2016; 23:53-59. [PubMed: 26918415]

36. Hering BJ, O'Connell PJ. First update of the International Xenotransplantation Association consensus statement on conditions for undertaking clinical trials of porcine islet products in type 1 diabetes--Chapter 6: patient selection for pilot clinical trials of islet xenotransplantation. Xenotransplantation. 2016; 23:60-76. [PubMed: 26918540]

37. Matsumoto S, Abalovich A, Wechsler C, Wynyard S, Elliott RB. Clinical Benefit of Islet Xenotransplantation for the Treatment of Type 1 Diabetes. EBioMedicine. 2016; 12:255-262. * A small clinical trial in wild-type neonatal pig islet xenotransplantation. [PubMed: 27592597]

38. Ekser B, Bottino R, Cooper DK. Clinical Islet Xenotransplantation: A Step Forward. EBioMedicine. 2016; 12:22-23. [PubMed: 27693105]

39. Cooper DK, Matsumoto S, Abalovich A, et al. Progress in Clinical Encapsulated Islet Xenotransplantation. Transplantation. 2016; 100:2301-2308. [PubMed: 27482959] 
40. Gazda LS, Collins J, Lovatt A, et al. A comprehensive microbiological safety approach for agarose encapsulated porcine islets intended for clinical trials. Xenotransplantation. 2016; 23:444-463. [PubMed: 27862363]

41. Park HS, Kim JW, Lee SH, et al. Antifibrotic effect of rapamycin containing polyethylene glycolcoated alginate microcapsule in islet xenotransplantation. J Tissue Eng Regen Med. 2017; 11:1274-1284. [PubMed: 26043934]

42. Kim MJ, Hwang YH, Kim YH, Lee DY. Immunomodulation of cell-penetrating tat-metallothionein for successful outcome of xenotransplanted pancreatic islet. J Drug Target. 2017; 25:350-359. [PubMed: 27829285]

43. Haque MR, Kim J, Park H, et al. Xenotransplantation of layer-by-layer encapsulated non-human primate islets with a specified immunosuppressive drug protocol. J Control Release. 2017; 258:1021. [PubMed: 28433740]

44. Shin JS, Kim JM, Kim JS, et al. Long-term control of diabetes in immunosuppressed nonhuman primates (NHP) by the transplantation of adult porcine islets. Am J Transplant. 2015; 15:28372850 . * The longest survival of wild-type pig islet xenotransplantation in nonhuman primates. [PubMed: 26096041]

45. Kang HJ, Lee H, Park EM, Kim JM, Min BH, Park CG. D-dimer level, in association with humoral responses, negatively correlates with survival of porcine islet grafts in non-human primates with immunosuppression. Xenotransplantation. 2017; 24doi: 10.1111/xen.12299

46. Kim JM, Shin JS, Min BH, et al. Induction, management, and complications of streptozotocininduced diabetes mellitus in rhesus monkeys. Xenotransplantation. 2016; 23:472-478. [PubMed: 27677911]

47. Lee HS, Lee JG, Yeom HJ, et al. The Introduction of Human Heme Oxygenase-1 and Soluble Tumor Necrosis Factor-a Receptor Type I With Human IgG1 Fc in Porcine Islets Prolongs Islet Xenograft Survival in Humanized Mice. Am J Transplant. 2016; 16:44-57. [PubMed: 26430779]

48. Arefanian H, Tredget EB, Mok DC, et al. Porcine Islet-Specific Tolerance Induced by the Combination of Anti-LFA-1 and Anti-CD154mAbs Is Dependent on PD-1. Cell Transplant. 2016; 25:327-342. [PubMed: 26109574]

49. Hawthorne WJ, Lew AM, Thomas HE. Genetic strategies to bring islet xenotransplantation to the clinic. Curr Opin Organ Transplant. 2016; 21:476-483. * A recent review which reports important genetic strategies in islet xenotransplantation. [PubMed: 27517501]

50. Bottino R, Knoll MF, Graeme-Wilson J, et al. Safe use of anti-CD154 monoclonal antibody in pig islet xenotransplantation in monkeys. Xenotransplantation. 2017; 24doi: 10.1111/xen.12283

51. Liu Z, Hu W, He T, et al. Pig-to-primate islet xenotransplantation: past, present, future. Cell Transplant. 2017; 26:925-947. ** A seminal review article in islet xenotransplantation in its past, present and future. [PubMed: 28155815]

52. Lee W, Miyagawa Y, Long C, et al. Expression of NeuGc on Pig Corneas and Its Potential Significance in Pig Corneal Xenotransplantation. Cornea. 2016; 35:105-113. [PubMed: 26418433]

53. Lee W, Hara H, Ezzelarab MB, et al. Initial in vitro studies on tissues and cells from GTKO/CD46/ NeuGcKO pigs. Xenotransplantation. 2016; 23:137-150. [PubMed: 26988899]

54. Dong X, Hara H, Wang Y, et al. Initial study of a 1,3-galactosyltransferase gene-knockout/CD46 pig full-thickness corneal xenografts in rhesus monkeys. Xenotransplantation. 2017; 24doi: $10.1111 /$ xen. 12282

55. Lee W, Mammen A, Dhaliwal DK, et al. Development of retrocorneal membrane following pig-tomonkey penetrating keratoplasty. Xenotransplantation. 2017; 24doi: 10.1111/xen.12276

56. Kim J, Kim DH, Choi HJ, et al. Anti-CD40 antibody-mediated costimulation blockade promotes long-term survival of deep-lamellar porcine corneal grafts in non-human primates. Xenotransplantation. 2017; 24(3) * Reports the longest survival in corneal xenotransplantation in nonhuman primates. doi: 10.1111/xen.12298

57. Kim DH, Kim J, Jeong HJ, Lee HJ, Kim MK, Wee WR. Biophysico-functional compatibility of Seoul National University (SNU) miniature pig cornea as xenocorneal graft for the use of human clinical trial. Xenotransplantation. 2016; 23:202-210. [PubMed: 27170205]

58. Reuven EM, Leviatan Ben-Arye S, Marshanski T, et al. Characterization of immunogenic Neu5Gc in bioprosthetic heart valves. Xenotransplantation. 2016; 23:381-392. [PubMed: 27610947] 
59. Lee W, Long C, Ramsoondar J, et al. Human antibody recognition of xenogeneic antigens (NeuGc and Gal) on porcine heart valves: could genetically modified pig heart valves reduce structural valve deterioration? Xenotransplantation. 2016; 23:370-380. [PubMed: 27511593]

60. Tena AA, Sachs DH, Mallard C, et al. Prolonged Survival of Pig Skin on Baboons After Administration of Pig Cells Expressing Human CD47. Transplantation. 2017; 101:316-321. [PubMed: 27232934]

61. Machaidze Z, Yeh H, Wei L, et al. Testing of microencapsulated porcine hepatocytes in a new model of fulminant liver failure in baboons. Xenotransplantation. 2017; 24doi: 10.1111/xen.12297

62. Mahou R, Passemard S, Carvello M, et al. Contribution of polymeric materials to progress in xenotransplantation of microencapsulated cells: a review. Xenotransplantation. 2016; 23:179-201. [PubMed: 27250036]

63. Iwase H, Liu H, Schmelzer E, et al. Transplantation of hepatocytes from genetically engineered pigs into baboons. Xenotransplantation. 2017 Mar.24doi: 10.1111/xen.12289

64. Aron Badin R, Vadori M, Vanhove B, et al. Cell Therapy for Parkinson's Disease: A Translational Approach to Assess the Role of Local and Systemic Immunosuppression. Am J Transplant. 2016; 16:2016-2029. ** A comprehensive report of pig neuronal cell xenotransplantation in nonhuman primates under the European Xenome Project. [PubMed: 26749114]

65. Cavicchioli L, Ferraresso S, Westmoreland S, et al. Posttransplant Lymphoproliferative Disorders in Neuronal Xenotransplanted Macaques. Vet Pathol. 2017; 54:336-344. [PubMed: 27694423]

66. Ezzelarab MB, Ekser B, Azimzadeh A, et al. Systemic inflammation in xenograft recipients precedes activation of coagulation. Xenotransplantation. 2015; 22:32-47. [PubMed: 25209710]

67. Iwase H, Ekser B, Hara H, et al. Thyroid hormone: relevance to xenotransplantation. Xenotransplantation. 2016; 23:293-299. [PubMed: 27374212]

68. Iwase H, Liu H, Li T, et al. Therapeutic regulation of systemic inflammation in xenograft recipients. Xenotransplantation. 2017; 24(2)doi: 10.1111/xen.12296

69. Li T, Lee W, Hara H, et al. An investigation of extracellular histones in pig-to-human organ xenotransplantation. Transplantation. 2017 Feb 3.doi: 10.1097/TP.0000000000001676

70. Denner J. Recent Progress in Xenotransplantation, with Emphasis on Virological Safety. Ann Transplant. 2016; 21:717-727. [PubMed: 27872471]

71. Denner J, Mueller NJ. Preventing transfer of infectious agents. Int J Surg. 2015; 23(Pt B):306-311. [PubMed: 26316157]

72. Denner J. How Active Are Porcine Endogenous Retroviruses (PERVs)? Viruses. 2016; 8:E215. [PubMed: 27527207]

73. Argaw T, Colon-Moran W, Wilson C. Susceptibility of porcine endogenous retrovirus to antiretroviral inhibitors. Xenotransplantation. 2016; 23:151-158. [PubMed: 27028725]

74. Yang L, Güell M, Niu D, et al. Genome-wide inactivation of porcine endogenous retroviruses (PERVs). Science. 2015; 350:1101-1104. * The use of CRISPR technology on the inactivation of PERV. [PubMed: 26456528]

75. Morozov VA, Wynyard S, Matsumoto S, Abalovich A, Denner J, Elliott R. No PERV transmission during a clinical trial of pig islet cell transplantation. Virus Res. 2017; 227:34-40. [PubMed: 27677465]

76. Choi HJ, Kim J, Kim JY, et al. Long-term safety from transmission of porcine endogenous retrovirus after pig-to-non-human primate corneal transplantation. Xenotransplantation. 2017 May 14.doi: 10.1111/xen.12314

77. Morozov VA, Plotzki E, Rotem A, Barkai U, Denner J. Extended microbiological characterization of Göttingen minipigs: porcine cytomegalovirus and other viruses. Xenotransplantation. 2016; 23:490-496. [PubMed: 27615035]

78. Denner J, Mankertz A. Porcine Circoviruses and Xenotransplantation. Viruses. 2017; 9:E83. [PubMed: 28425928]

79. Olver IN. Ethical issues with xenotransplantation clinical trials. Med J Aust. 2016; 204:212. [PubMed: 27031388]

80. Abalovich A, Matsumoto S, Wechsler CJ, et al. Level of acceptance of islet cell and kidney xenotransplants by personnel of hospitals with and without experience in clinical xenotransplantation. Xenotransplantation. 2017 Jun 17.doi: 10.1111/xen.12315 
81. Mathieu R. Jewish ethics and xenotransplantation. Xenotransplantation. 2016; 23:258-268. [PubMed: 27388035]

82. Ríos A, López-Navas AI, Martínez-Alarcón L, et al. Acceptance of organ xenotransplantation among Latin American immigrants resident in the United States. Xenotransplantation. 2016; 23:269-278. [PubMed: 27422340]

83. Paris W, Jang K, Colsch L, et al. Psychosocial challenges of xenotransplantation: the need for a multidisciplinary, religious, and cultural dialogue. Xenotransplantation. 2016; 23:335-337. [PubMed: 27613198]

84. Schuurman HJ. Regulatory aspects of clinical xenotransplantation. Int J Surg. 2015; 23(Pt B):312321. ** Seminal review article in regulatory aspects of clinical xenotransplantation both in the United States and Europe. [PubMed: 26408947]

85. Schuurman HJ. Microbiological safety of clinical xenotransplantation products: monitoring strategies and regulatory aspects. A commentary. Xenotransplantation. 2016; 23:440-443. [PubMed: 27859642]

86. Butler JR, Tector AJ. CRISPR genome-editing: a medical revolution. J Thorac Cardiovasc Surg. 2017; 153:488-491. * Important review on the impact of CRISPR genome-editing in xenotransplantation research. [PubMed: 28104200]

87. Kim GA, Lee EM, Jin JX, et al. Generation of CMAHKO/GTKO/shTNFRI-Fc/HO-1 quadruple gene modified pigs. Transgenic Res. 2017 May 28.doi: 10.1007/s11248-017-0021-6

88. Butler JR, Santos RMN, Martens GR, et al. Efficient generation of targeted and controlled mutational events in porcine cells using nuclease-directed homologous recombination. J Surg Res. 2017; 212:238-245. [PubMed: 28550913]

89. Niemann H, Petersen B. The production of multi-transgenic pigs: update and perspectives for xenotransplantation. Transgenic Res. 2016; 25:361-374. [PubMed: 26820415]

90. Fischer K, Kraner-Scheiber S, Petersen B, et al. Efficient production of multi-modified pigs for xenotransplantation by 'combineering', gene stacking and gene editing. Sci Rep. 2016; 6:29081. [PubMed: 27353424]

91. Kwon DJ, Kim DH, Hwang IS, et al. Generation of a-1,3-galactosyltransferase knocked-out transgenic cloned pigs with knocked-in five human genes. Transgenic Res. 2017; 26:153-163. [PubMed: 27554374]

92. Gao H, Zhao C, Xiang X, et al. Production of a1,3-galactosyltransferase and cytidine monophosphate-N-acetylneuraminic acid hydroxylase gene double-deficient pigs by CRISPR/ Cas9 and handmade cloning. J Reprod Dev. 2017; 63:17-26. [PubMed: 27725344]

93. Petersen B, Frenzel A, Lucas-Hahn A, et al. Efficient production of biallelic GGTA1 knockout pigs by cytoplasmic microinjection of CRISPR/Cas9 into zygotes. Xenotransplantation. 2016; 23:338346. [PubMed: 27610605]

94. Hwang JH, Kim SE, Gupta MK, Lee H. Gnotobiotic Miniature Pig Interbreed Somatic Cell Nuclear Transfer for Xenotransplantation. Cell Reprogram. 2016; 18:207-213. [PubMed: 27459580]

95. Salomon DR. A CRISPR Way to Block PERVs--Engineering Organs for Transplantation. N Engl J Med. 2016; 374:1089-1091. [PubMed: 26981939]

96. Butler JR, Skill NJ, Priestman DL, et al. Silencing the porcine iGb3s gene does not affect Gala3Gal levels or measures of anticipated pig-to-human and pig-to-primate acute rejection. Xenotransplantation. 2016; 23:106-116. [PubMed: 27106872]

97. Martens GR, Reyes LM, Butler JR, et al. Humoral Reactivity of Renal Transplant-Waitlisted Patients to Cells from GGTA1/CMAH/B4GalNT2, and SLA Class I Knockout Pigs. Transplantation. 2017; 101:e86-e92. ** Important research article testing human samples against triple knock-out pig and SLA Class I knock-out pig in order to understand and select potential recipients for future clinical trials. [PubMed: 28114170]

98. Butler JR, Martens GR, Estrada JL, et al. Silencing porcine genes significantly reduces humananti-pig cytotoxicity profiles: an alternative to direct complement regulation. Transgenic Res. 2016; 25:751-759. [PubMed: 27100221] 
99. Butler JR, Paris LL, Blankenship RL, et al. Silencing Porcine CMAH and GGTA1 Genes Significantly Reduces Xenogeneic Consumption of Human Platelets by Porcine Livers. Transplantation. 2016; 100:571-576. [PubMed: 26906939]

100. Paris LL, Estrada JL, Li P, et al. Reduced human platelet uptake by pig livers deficient in the asialoglycoprotein receptor 1 protein. Xenotransplantation. 2015; 22:203-210. [PubMed: 25728617]

101. Cooper DK. Modifying the sugar icing on the transplantation cake. Glycobiology. 2016; 26:571581. [PubMed: 26935763]

102. Cowan PJ, Rieben R. Modifying the Glycome in Pigs for Xenotransplantation. Transplantation. 2016; 100:485-486. [PubMed: 26906937]

103. Cooper DK, Ezzelarab MB, Hara H, et al. The pathobiology of pig-to-primate xenotransplantation: a historical review. Xenotransplantation. 2016; 23:83-105. ** Seminal review in the pathobiology of pig-to-primate xenotransplantation. [PubMed: 26813438]

104. Cooper DK. Is successful orthotopic heart transplantation in the pig-to-non-human primate model required before proceeding to a clinical trial? Xenotransplantation. 2016; 23:328-329. [PubMed: 27412907]

105. Cowan PJ, Ierino FL. Reducing the Threshold for Clinical Renal Xenotransplantation. Transplantation. 2017; 101:692-693. * An intriguing commentary for the future application of renal xenotransplantation. [PubMed: 28099406]

106. Samy KP, Butler JR, Li P, Cooper DK, Ekser B. The role of costimulation blockade in solid organ and islet xenotransplantation. J Immunol Res. 2017 in press * A recent comprehensive review on the impact of different costimulation blockade agents in solid organ as well as islet xenotransplantation.

107. Buermann A, Römermann D, Baars W, Hundrieser J, Klempnauer J, Schwinzer R. Inhibition of B-cell activation and antibody production by triggering inhibitory signals via the PD-1/PD-ligand pathway. Xenotransplantation. 2016; 23:347-356. [PubMed: 27613101]

108. Cowan PJ, Tector AJ. The Resurgence of Xenotransplantation. Am J Transplant. 2017 Apr 11. * An important commentary on the future of xenotransplantation. doi: 10.1111/ajt.14311

109. Marx H, Hahne H, Ulbrich SE, et al. Annotation of the Domestic Pig Genome by Quantitative Proteogenomics. J Proteome Res. 2017 Jun 29.doi: 10.1021/acs.jproteome.7b00184 


\section{KEY POINTS}

- In the last 24 months, prolonged survivals were achieved in heart, kidney, liver, islet, and corneal xenotransplantation with the use of geneticallyengineered pigs and/or newer costimulation blockade agents.

- Thanks to the CRISPR technology, the production of multiple-gene pigs is easier and faster and more genetically-engineered pigs are now available for xenotransplantation research.

- The International Xenotransplantation Association has recently published the first update of the consensus statement on conditions for undertaking clinical trials of porcine islet products.

- $\quad$ First-in-man explorations (in some organs), and/or clinical (solid organ, islet, or tissue) xenotransplantation trials might start sooner than expected. 


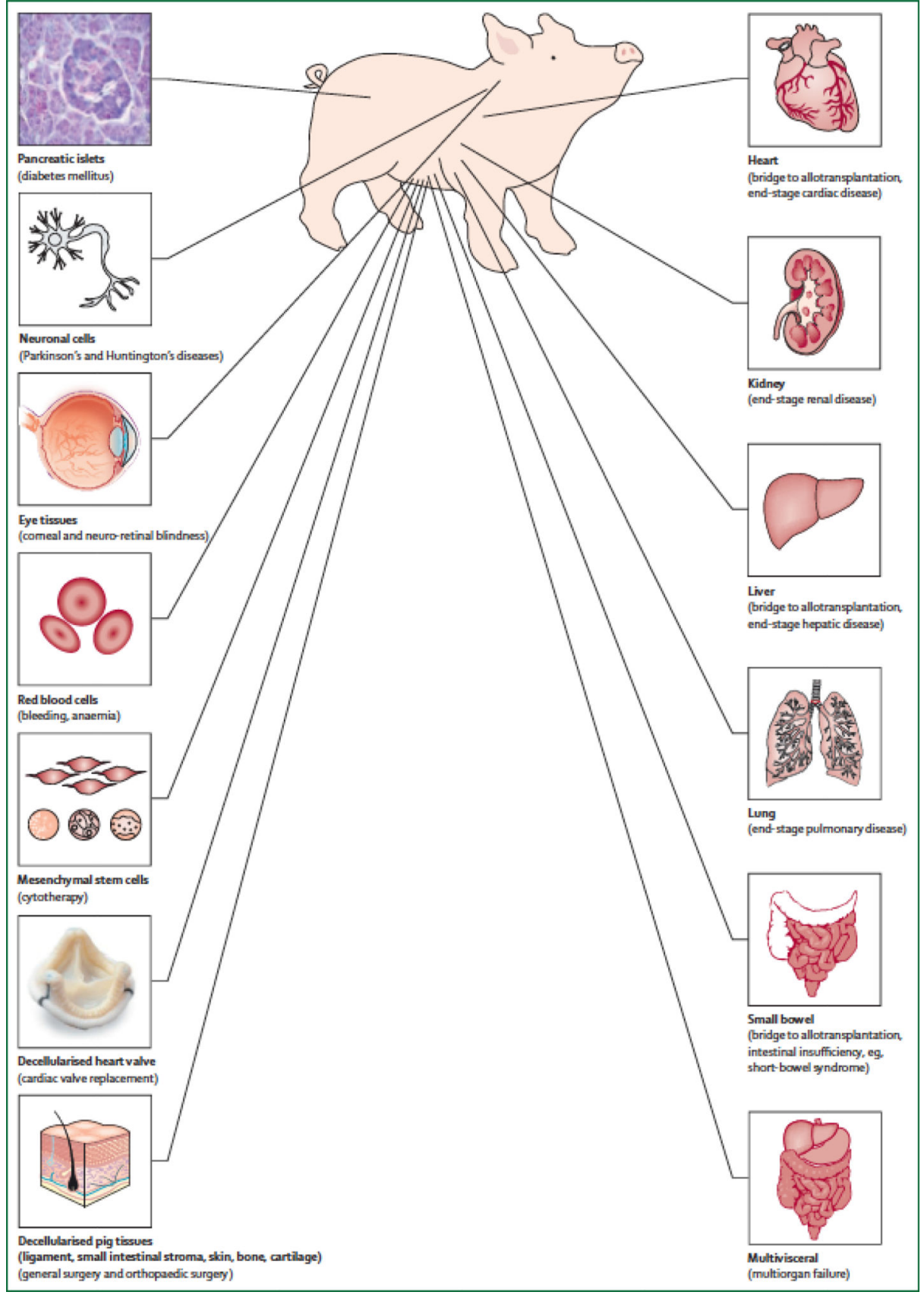

Figure 1. Disorders for which xenotransplantation is a potential therapy*

* Reproduced with permission from Ekser et al [2]. 


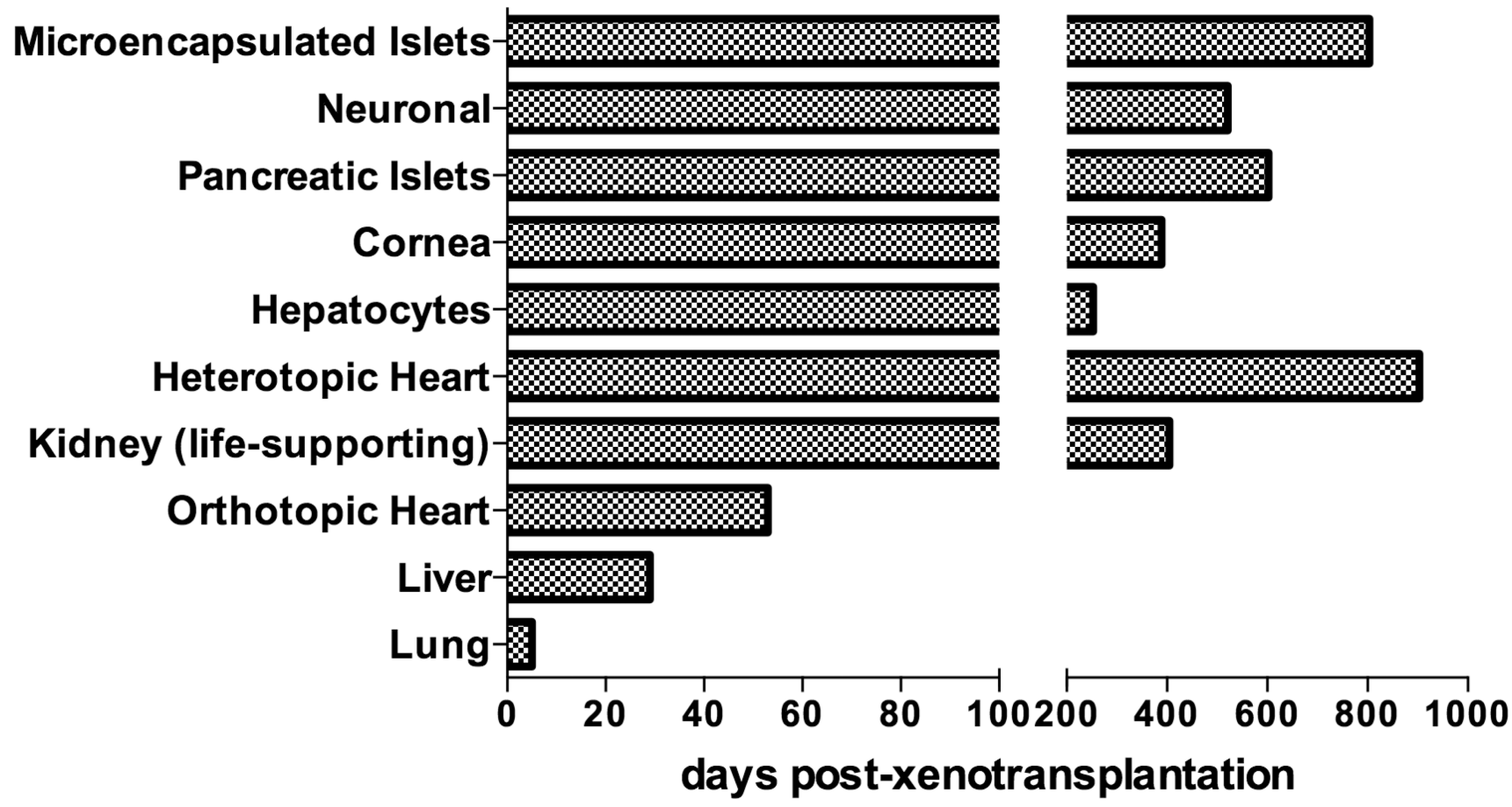

Figure 2. Longest survival times of organ and cell xenotransplantation from pigs to nonhuman primates

Microencapsulated pancreatic xeno-islets survived for 804 days with retransplantation, but 250 days without retransplantation. Neuronal xeno-cells survived for 521 days. Pancreatic xeno-islets survived for $>603$ days. Corneal (deep-lamellar) xenografts survived for $>389$ days. Xeno-hepatocytes survived for 243 days with retransplantation, but 80 days without retransplantation. Heterotopic xeno-heart survived for $>900$ days. Kidney xenograft (lifesupporting) survived for 405 days. Orthotopic xeno-heart survived for 57 days. Liver xenograft survived for 29 days. Lung xenograft survived for 5 days. 


\section{Table 1}

Timeline for application of evolving techniques for genetic engineering of pigs employed in xenotransplantation.

\begin{tabular}{|c|l|}
\hline Year & Technique \\
\hline 1992 & Microinjection of randomly integrating transgenes \\
\hline 2000 & Somatic cell nuclear transfer (SCNT) \\
\hline 2002 & Homologous recombination \\
\hline 2011 & Zinc finger nucleases (ZFNs) \\
\hline 2013 & Transcription activator-like effector nucleases (TALENs) \\
\hline 2014 & CRISPR/Cas9 \\
\hline
\end{tabular}

CRISPR/Cas9, clustered randomly interspaced short palindromic repeats and the associated protein 9. (Table adopted from Cooper et al.) [8] 


\section{Table 2}

Selected genetically-modified pigs currently available for xenotransplantation research*

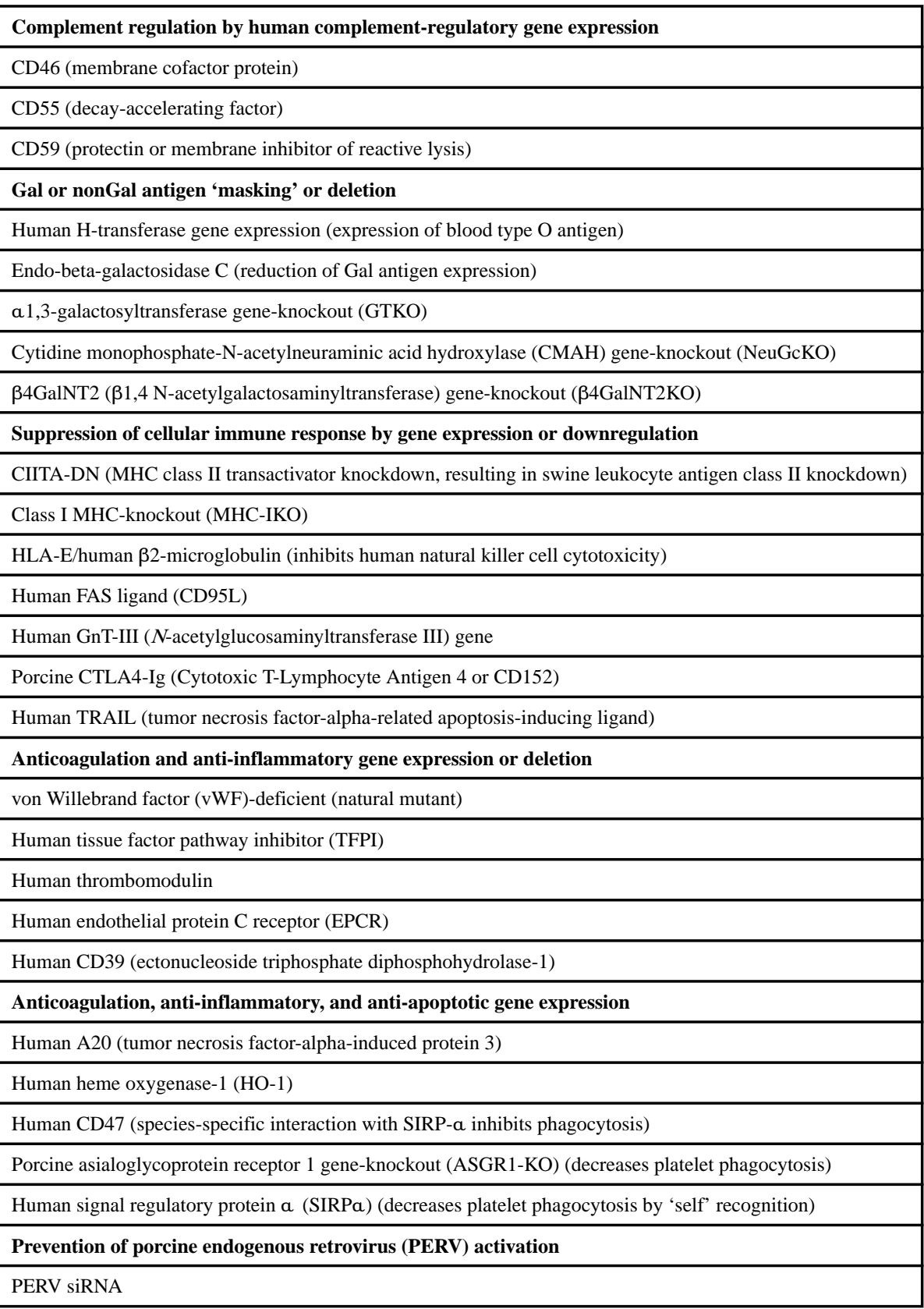

Reproduced with permission from Ekser et al [2] Cooper et al [8]. 